\title{
Primer curso del IAPH a través de Internet
}

Este año el Departamento de Formación del IAPH oferta por primera vez un curso de especialización a distancia a través de Internet. El curso a impartir será "Organización y explotación de recursos digitales del patrimonio histórico en Internet", y estará organizado en colaboración con la Asociación Andaluza de Documentalistas (AAD).

Esta iniciativa responde a la apuesta del Instituto Andaluz del Patrimonio Histórico por ampliar y actualizar las fórmulas de formación, aplicando avanzados instrumentos e innovadores métodos a su oferta formativa. El alcance e incidencia de las tecnologías de la información y de las comunicaciones es hoy una realidad que afecta a todos los sectores de la sociedad.

Por ello consideramos de interés prioritario la promoción de cursos de especialización del patrimonio histórico mediante la formación a distancia a través de Internet. Esta modalidad de formación amplía la cobertura geográfica y temporal de nuestra oferta, libre de las condiciones espacio-tiempo, evitando las limitaciones de desplazamientos y horario fijo de los cursos presenciales.

Asimismo, el nuevo entorno tecnológico exige estar al día de las posibilidades y usos de herramientas informativas, tanto para el diseño y creación de recursos digitales de calidad como para el conocimiento y explotación de los recursos disponibles en Internet. Por ello, el acercamiento a distintos aspectos de la documentación digital y el conocimiento de los recursos electrónicos de información se plantea en el momento actual como una ineludible necesidad para la formación de los profesionales de la documentación y del patrimonio histórico.

Este curso pretende, por un lado, que el alumno conozca y utilice la teleformación como un nuevo método de aprendizaje $y$, por otro lado, que adquiera los conocimientos necesarios para la creación y organización de la información digital y para la explotación de los recursos digitales en general y del patrimonio histórico en particular.

Está dirigido a los profesionales de la información interesados en el conocimiento de las técnicas para la organización y explotación de recursos digitales, así como a los profesionales del patrimonio histórico que requieran un acercamiento a la documentación digital y a su aplicación al ámbito patrimonial.

El número de plazas estimada para el adecuado desarrollo y seguimiento del curso es de 30 alumnos. Para poder participar será requisito indispensable que el alumno posea unos conocimientos informáticos a nivel de usuarios: herramientas de navegación, correo electrónico, etc., y que disponga de acceso a Internet y cuenta de correo electrónico.

La fecha prevista para la realización del curso son las tres primeras semanas de junio de $200 \mathrm{I}$. El curso se iniciará el día I de junio y permanecerá abierto hasta el día 15 de junio, ambos inclusive. En este período los alumnos tendrán acceso al programa completo (presentación, pretest, unidades, tests de autoevaluación). Además, del 5 al 9 de junio se activarán otras actividades de participación del alumnado como foros-debates, tablón del profesor, ejercicios finales, etc., paralelamente a la atención online del profesor a las cuestiones generales o específicas. El día 15 de junio se cerrará la participación del alumnado y la atención del profesor, aunque permanecerá abierto el programa completo hasta la realización de la evaluación de los alumnos, el día 22 de junio de 2001.

El número total de horas se equipará al de un curso presencial de 20 horas de duración. Para la obtención del certificado será necesario realizar los test de cada unidad, participar en los foros-debates y superar el ejercicio final de evaluación.

El programa del curso se articulará en unidades didácticas que permitan al alumnado el acercamiento escalonado a los siguientes conocimientos básicos:

- Internet y la Documentación e Información: utilidades y aplicaciones.

- Creación y organización de la información digital.

- Explotación de los recursos digitales en Internet.

- Principales recursos especializados en patrimonio histórico.

- Desafíos.

El desarrollo de los contenidos así como las posibles ampliaciones o modificaciones se concretarán y difundirán a través de un tríptico informativo y de las páginas web del IAPH y de la AAD.

Isabel Ortega Vaquero Directora del curso 